\title{
Sex steroid receptors and apoptosis-related proteins are differentially expressed in polycystic ovaries of adult dogs
}

\author{
Luiz Gustavo de Almeida Chuffa ${ }^{\mathrm{a}, *}$, Luiz Antonio Lupi Júnior ${ }^{\mathrm{a}}$, Alfredo Feio da Maia Lima ${ }^{\mathrm{b}}$ \\ a Department of Anatomy, Biosciences Institute, UNESP - Univ. Estadual Paulista, Botucatu, SP 18618-970, Brazil \\ ${ }^{\mathrm{b}}$ Department of Veterinary, Faculty of Veterinary Medicine and Zootechny, UNESP - Univ. Estadual Paulista, Botucatu, SP 18618-970, Brazil
}

\section{A R T I C L E I N F O}

\section{Article history:}

Received 10 September 2015

Received in revised form

18 December 2015

Accepted 18 December 2015

Available online 23 December 2015

\section{Keywords:}

Polycystic ovary

Sex steroid receptors

AR

ER

Apoptosis

Dog

\begin{abstract}
A B S T R A C T
In Polycystic Ovaries (PCOs), the dynamics of sex hormone receptors and follicle-related apoptotic signaling remain unknown. In this study, we investigated the expression of androgen receptors (AR), estrogen receptors (ER $\alpha$ and $E R \beta$ ), and apoptosis-related molecules (BAX, active caspase-3, Bcl-2 and Survivin) on different follicular stages of PCOs in adult dogs. Clinical evidences of high estradiol and testosterone levels, persistent estrus and vaginal discharge were observed. Inhibin B immunolabeling was increased in primary and 2 to $5-\mathrm{mm}$ follicles, and a marked epithelial hyperplasia was common in the ovarian surface. Ovarian epithelia and primary follicles showed low expression of AR, ER $\alpha$, and ER $\beta$, whereas a moderate immunoexpression of AR was found in theca cells of secondary follicles and cysts. In PCOs, growing follicles displayed ER $\alpha$ expression, and secondary follicles exhibited higher ER $\beta$ expression. In addition, while few ER $\alpha$-positive cells were found in the cysts, ER $\beta$ was moderately expressed in growing follicles and cysts. BAX was upregulated in the ovarian epithelium, primary follicles, and in the wall of follicular cysts. Active caspase-3 was significantly downregulated in the epithelium, primary follicles, and follicular cysts, whereas growing follicles had a strong immunoexpression in the granulosa cells. $\mathrm{Bcl}-2$ and survivin were increased in the epithelium and primary follicles, and only survivin was upregulated in secondary and growing follicles. While Bcl-2 had a diffuse immunexpression in the follicular cysts, survivin was overexpressed by these cells. We concluded that sex steroid receptors and apoptotic proteins are differentially expressed in the follicles of adult dogs with PCOs.
\end{abstract}

(c) 2015 Elsevier Ltd. All rights reserved.

\section{Introduction}

Polycystic ovary syndrome is a common pathophysiological condition affecting women at reproductive age, characterized by chronic anovulation, polycystic ovaries, hyperandrogenism, and insulin resistance (Magoffin and Jakimiuk, 1998). Although it is a heterogeneous disorder of unclear etiology, there is evidence of genetic component as well as environmental factors (e.g. alterations in the expression and activity of sex steroid receptors (Xita et al., 2002; Palioura and Diamanti-Kandarakis, 2013)).

Laboratory examination has detected an increase in androgen levels, which are linked to inhibition of follicle development, anovulation, menstrual changes, and microcysts in the ovaries

\footnotetext{
* Corresponding author at: Department of Anatomy, Bioscience Institute, UNESP - Univ. Estadual Paulista, Zip Code: 510, P.O Box: 18618-970, Rubião Júnior, s/n, Botucatu, SP, Brazil.

E-mail address: chuffa@ibb.unesp.br (L.G.d.A. Chuffa).
}

(Lombardi et al., 2012), but no description of their ovarian receptors is provided. Importantly, experimental evidence indicated that intrauterine exposure to androgens is associated with development of PCOs (Xita and Tsatsoulis, 2006).

In canines, the diagnosis of bitches with follicular cysts often occurs around 8 years of age. Concurrent diseases observed in dogs bearing ovarian cysts include cystic endometrial hyperplasia, pyometra, mammary neoplasia, ovarian and uterine neoplasias, and skin alterations, characteristic of hyperestrogenism, lichenification, and hyperkeratosis (Johnston et al., 2001). In animal models and humans, it is well-established the role of folliclestimulating hormone (FSH) and luteinizing hormone (LH) and their receptor gene polymorphisms on follicular development and PCOs (Bogovich, 2007; Singhasena et al., 2014; Wu et al., 2014). Unfortunately, there is no information concerning sex hormone receptors related to PCOs in dogs. Because sex steroid receptors orchestrate a variety of ovarian events such as folliculogenesis, luteogenesis, and even ovulation, a better knowledge of how these receptors work in canine PCOs might be useful for exploring new strategies of treatment. 
Apoptosis is a natural event responsible for ovarian functions. There are many hormonal and intracellular factors coordinating life and cell death during the development and maintenance of ovarian activity (Tilly, 1996). In experimental PCOs, the involvement of $\mathrm{Bcl}-2$, an anti-apoptotic member, seems to be important during the transformation of growing follicles into cystic follicles (Bas et al., 2011). Bcl-2 activity is associated with another recently described protein termed BAX, which probably acts independently of Bcl-2 heterodimerization to induce apoptosis (Tilly, 1996). Survivin is a member of the inhibitor of apoptosis protein (IAP) family involved in mitosis regulation and inhibition of apoptosis (Jiang et al., 2014). Conditional deletion of survivin in granulosa cells is associated with compromised follicle development and ovulation leading to defective ovarian function and subfertility (Jiang et al., 2014). To date, no study has been conducted to trace the relationship between apoptotic and anti-apoptotic signals in different follicles of PCOs.

We therefore aimed to investigate the expression and distribution of sex steroid receptors (AR, ER $\alpha$ and $\beta$ ) and apoptosis-related molecules (BAX, Active caspase-3, Bcl-2, and Survivin) in adult dogs with PCOs. The dog is considered an excellent model for comparative studies of reproductive biology (Kirchhoff, 2002).

\section{Materials and methods}

\subsection{Animal and tissues}

Seven 7-year-old female dogs were presented with history of persistent estrus and vaginal discharge. Samples of the PCOs and control ovaries ( $n=07 /$ group) were obtained from adult Rottweiler dogs (Canis familiaris) during castration surgery performed at the Clinical Hospital of the Veterinary Medical School of UNESP at Botucatu. Large fragments of ovaries were collected, and rapidly immersed in $10 \%(\mathrm{v} / \mathrm{v})$ buffered formalin as fixative solution.

\subsection{Morphometry}

The PCOs were dissected under a surgical microscope D.F. Vasconcelos, and representative areas were dehydrated using $80 \%$, $90 \%, 95 \%$, and $100 \%$ alcohol for $4 \mathrm{~h}$, followed by diaphanization and paraplast embedding (Oxford Labware, St. Louis, USA). The blocks were sectioned at 5 - $\mu \mathrm{m}$-thickness using a LEICA 2145 microtome, and then stained with Hematoxilin-Eosin (HE). For this procedure, tissue sections were hydrated and stained with hematoxilin for 1 min (nuclear staining) followed by eosin for 1 min (cytoplasm staining). The slides were analyzed and captured by digital photomicroscope Axiophot II Zeiss. For histological analysis and follicle counting, every five slides per ovary in three different areas per section/animal were analyzed using $20 \times$ magnification (interval between the sections was $50 \mu \mathrm{m}$; Chuffa et al., 2009, 2013a,b). A general classification of the follicles in PCOs consisted of the following categories: (1) primary follicle were comprised of one layer of granulosa cells surrounding the oocyte; (2) secondary follicle were comprised of two to six layers of granulosa cells; (3) growing follicle were comprised of several granulosa cell layers with initial antrum (preantral follicles); (4) atretic follicle showed granulosa cells undergoing apoptosis and oocyte degeneration; (5) ovarian cysts with 2-9 $\mathrm{mm}$ in diameter and comprised of fluid collection and surrounded by a very thin follicular wall.

\subsection{Immunohistochemistry}

Sections of PCOs and control ovaries (20 randomly selected sections/ovary/dog) were deparaffinized in xylene based on the areas previously identified during the morphological analysis. Tissues were microwaved $(800 \mathrm{~W})$ while immersed in $0.01 \mathrm{M}$ sodium citrate buffer ( $\mathrm{pH}$ 6.0) for antigen retrieval. After blocking endogenous peroxidase activity, the tissues were incubated with 3\% BSA for $1 \mathrm{~h}$ to avoid non-specific binding. PCOs sections were then incubated in a humid chamber overnight at $4{ }^{\circ} \mathrm{C}$ with primary antibodies (Abcam Inc, MA, USA): mouse monoclonal anti-Pan-cytokeratin (1:100, ab7753), anti-AR (1:100, ab9474), anti-ER $\alpha$ (1:100, ab37438), anti-ER $\beta$ (1:100, ab3576), anti-BAX (1:50, ab7977), anti-active caspase-3 (1:100, ab2302), anti-Bcl-2 (1:100, ab7973), or antisurvivin (1:200, ab24479). After immunoreactions, the slides were washed in TBS-T and incubated with secondary biotinylated antibody (1:70 dilution), goat anti-rabbit IgG (Santa Cruz Biotechnology, Calif., USA). The slides were reacted with chromogen diaminobenzidine (DAB; Sigma, St. Louis, MO, USA) for $5 \mathrm{~min}$, and sections were counterstained with hematoxylin. Negative controls were obtained by omission of the primary antibody. IHC results were analyzed under a Zeiss Axiophot II microscope (Carl Zeiss, Oberkochen, Germany) based on the levels of staining intensity as absent, weak, moderate, and strong reactions, and percentage (\%) of positive cells for every 1000 or 100 counted cells by specific follicle size were obtained using Axionvision software v.4.8 (Carl Zeiss, Oberkochen, Germany).

\subsection{Immunofluorescence}

PCOs samples $(n=7)$ were washed with phosphate-buffered saline, fixed in $4 \%$ paraformaldehyde for $10 \mathrm{~min}$, and permeabilized with PBS at room temperature. Nonspecific binding sites were blocked with $1 \%$ bovine serum albumin (BSA) for $60 \mathrm{~min}$. Samples were incubated with anti-inhibin B primary polyclonal antibody (dilution $1: 100$, overnight at $4{ }^{\circ} \mathrm{C}$ ) followed by secondary polyclonal anti-rabbit IgG conjugated to FITC (1:200, sc-2012, Santa Cruz Biotechnology Inc., CA, USA) for $1 \mathrm{~h}$ at room temperature (RT). Nuclei were stained with 6-diamidino-2-phenylindole (DAPI, $5 \mathrm{~min}$ ) at RT. For negative immunolabeling, no primary antibody was added. Immunopositive cells were analyzed under a fluorescence microscope (Zeiss II, Oberkochen, Germany) at 40X magnification (excitation $590 \mathrm{~nm}$; emission filter $650 \mathrm{~nm}$ ) and for DAPI (excitation $365 \mathrm{~nm}$; emission filter $480 \mathrm{~nm}$ ). The quantification of fluorescence images was performed in different follicle sizes (percentage of positive cells/total cells).

\subsection{ELISA}

Blood samples were collected from cephalic vein and directly placed into conical sterile centrifuge tubes. Afterwards, serum was obtained by centrifugation at $1.200 \times \mathrm{g}$ for $15 \mathrm{~min}$ at $4{ }^{\circ} \mathrm{C}$ and stored at $-20^{\circ} \mathrm{C}$ until they were assayed. Serum levels of Testosterone (Catalog\# KA2297, Abnova, Walnut, CA, USA) and 17 $\beta$-estradiol (Catalog\# CA0961 Biotang) were measured by specific enzymelinked immunoassay (ELISA) and the reading was carried out in an Epoch spectrophotometer (Biotek, Winooski, VT, USA) according to the manufacturer's instructions.

\subsection{Statistical analysis}

The values are presented as the mean $\pm S D$, using total samples for analyses ( $n=07 /$ group). Student's $t$-test was performed for parametric data and Mann-Whitney $U$-test for non-parametric distribution. Significant results were set at $p<0.05$. Sigma Plot Version 12.5 graphing software was used.

\section{Results}

\subsection{General characteristics of PCOs in adult dog}

The clinical characteristics of PCOs are shown in Table 1. While PCOs had a $90.2 \%$ increase in ovarian area, there was a severe 

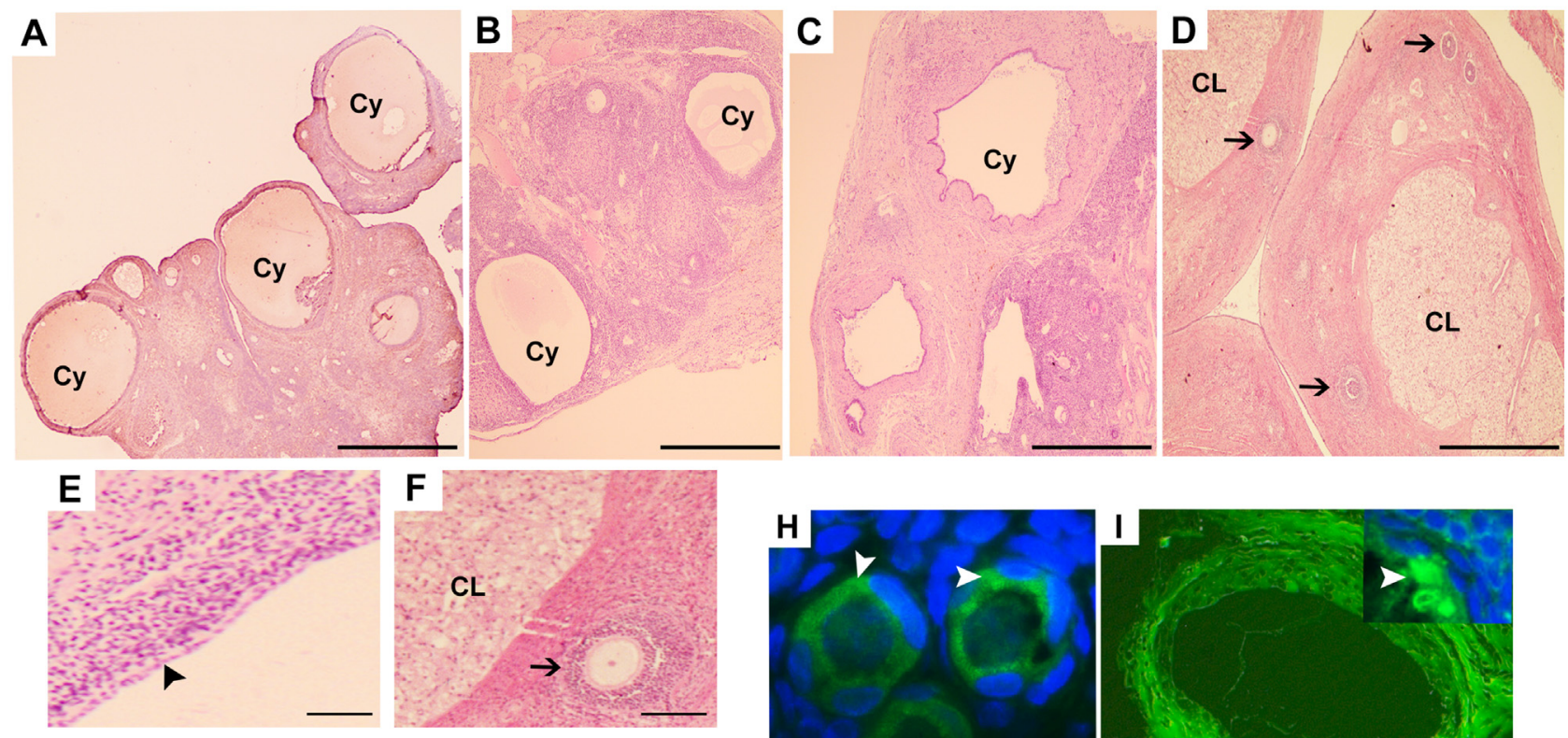

\section{G}
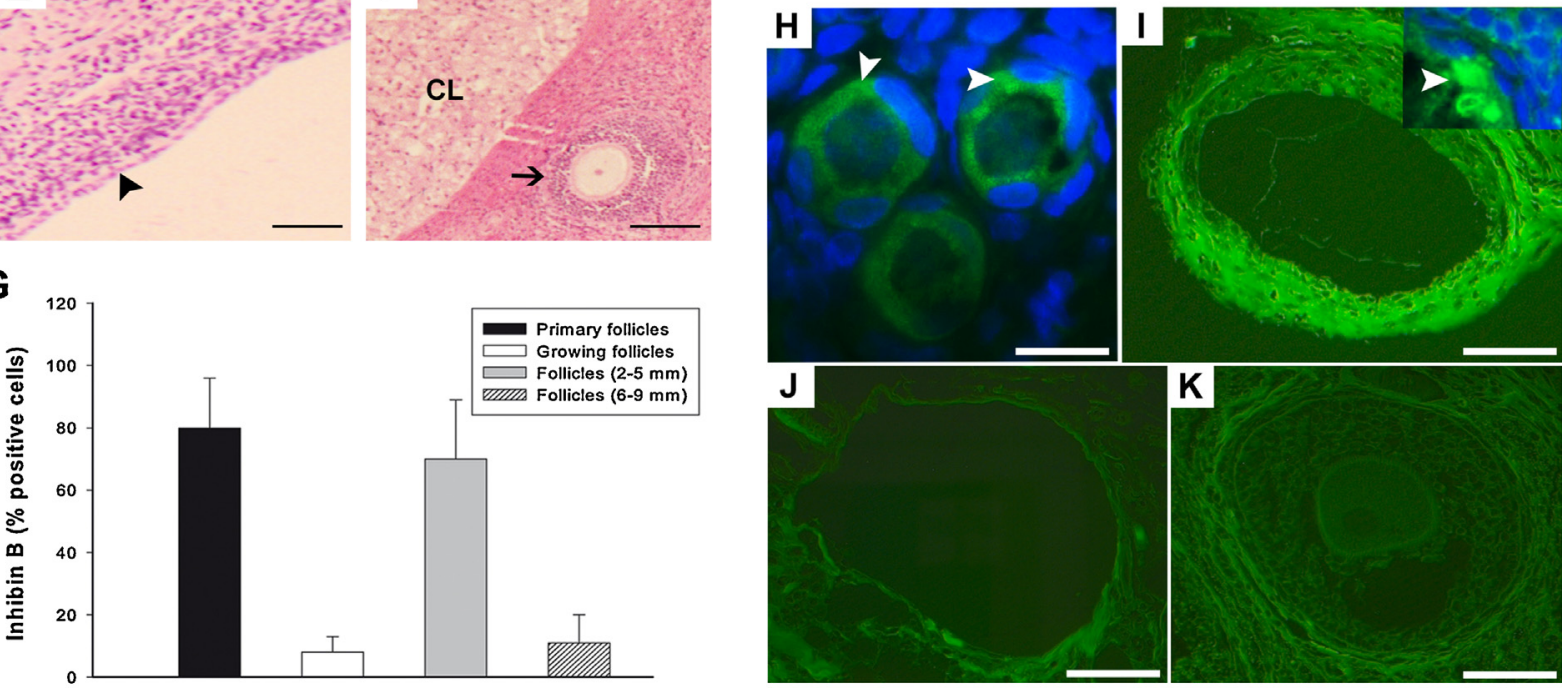

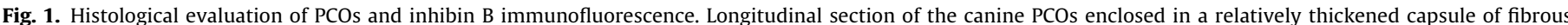

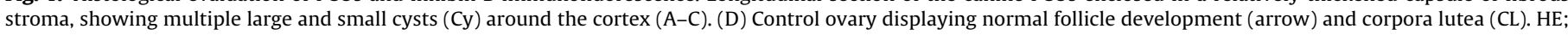

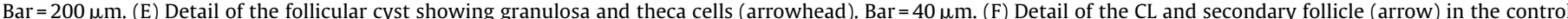

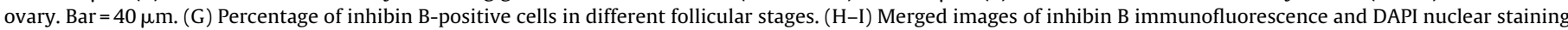

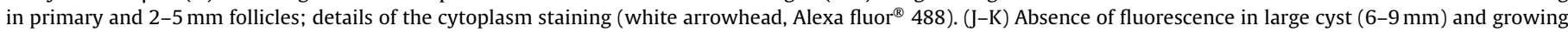
follicles. Bar $=40 \mu \mathrm{m} . N=07 /$ group.

Table 1

General characteristics of the polycystic ovaries (PCOs) and hormone levels in adult dogs ( $n=07 /$ group).

\begin{tabular}{lll}
\hline Parameters & Control & PCOs \\
\hline Age (years) & $7.0 \pm 0.5$ & $7.0 \pm 0.8$ \\
Ovarian area $\left(\mathrm{cm}^{2}\right)$ & $3.8 \pm 0.9$ & $7.7 \pm 1.3^{*}$ \\
Number of primary follicles & $42.4 \pm 8.4$ & $17.9 \pm 6.6^{*}$ \\
Number of growing follicles & $79.0 \pm 14.2$ & $20.3 \pm 7.1^{*}$ \\
Number of mature follicles & $6.0 \pm 1.7$ & Absent \\
Number of atretic follicles & $7.0 \pm 2.3$ & $4.0 \pm 1.9^{*}$ \\
Number of total corpora lutea & $22.0 \pm 6.8$ & Absent \\
Number of cysts & & \\
2-9 mm & 0 & $9 \pm 1$ \\
2-5 mm & 0 & $6 \pm 2$ \\
6-9 mm & 0 & $3 \pm 2$ \\
E2 levels $(\mathrm{pg} / \mathrm{mL})$ & $41.2 \pm 13.6$ & $119.4 \pm 23.8^{*}$ \\
T levels $(\mathrm{ng} / \mathrm{mL})$ & $0.22 \pm 0.07$ & $0.60 \pm 0.11^{*}$ \\
\hline
\end{tabular}

Student $t$-test. For number of cysts and E2 levels was used Mann-Whitney $U$-test. Data are expressed as the mean \pm SD. E2: $17-\beta$-estradiol, T: testosterone. $p<0.05$.

reduction in the number of primary, growing, and atretic follicles. In addition, mature follicles and corpora lutea were absent in PCOs. Follicular cysts characterized by a thin layer of theca cells and compacted granulosa cells varied according to the size and number (Table 1, Fig. 1A-F), and were ranged within categories of $2-9 \mathrm{~mm}$
( $\sim 9$ per ovary), $2-5 \mathrm{~mm}$ ( $\sim 6$ per ovary), and $6-9 \mathrm{~mm}$ ( $\sim 3$ per ovary) of follicular diameter. Notably, serum levels of $17 \beta$-estradiol (E2) and testosterone $(\mathrm{T})$ were elevated $(65.8 \%$ and $60 \%$ respectively vs. controls) in these animals as expected for PCOs (Table 1).

Because the arrest of follicular development in PCOs occurs when dominant follicles are selected, inhibin levels in the follicles may exert an important action. In this study, inhibin B was presented only in primary and $2-5 \mathrm{~mm}$ follicles (Fig. 1G, H, and I). Conversely, growing follicles and 6-9 $\mathrm{mm}$ follicles showed a discrete inhibin B immunolabeling (Fig. 1G, J, and K); fluorescence level reduced from $84 \% \pm 7.7$ to $23 \% \pm 9.3$.

\subsection{Ovarian surface epithelium and sex steroid receptors in different follicles of PCOs}

In PCOs, the ovarian surface epithelium displayed a marked hyperplasia with some papillary projections (Fig. 2A and B). A strong immunoreaction for Pan-cytokeratin (95\% of total positive cells) revealed that epithelial cells appeared located in multiple layers at the surface and showed no cellular atypias or pleomorphisms.

Differential expression of sex steroid receptors was analyzed in the PCOs and controls. Ovarian epithelia and primary follicles showed weak but continuous expression to AR, ER $\alpha$, and ER $\beta$ compared to controls (Table 2, Fig. 3A, B, D, H, I, K, O, Q and U). Although the number of AR-positive cells was significantly reduced in the 

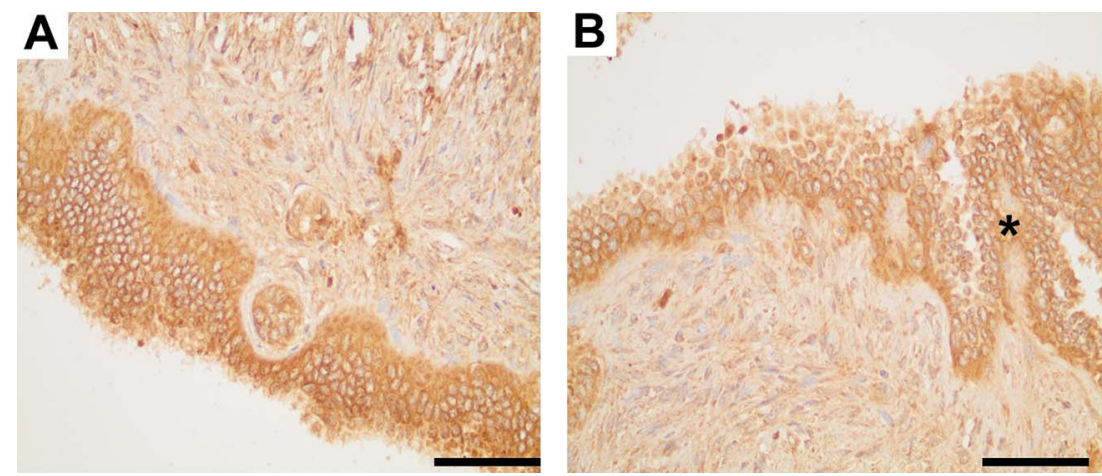

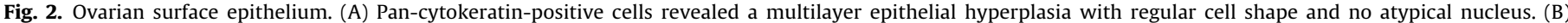
Papillomatosis $\left(^{*}\right)$ supported by a delicate fibrovascular stroma was common in specific areas of PCOs. Bar $=20 \mu \mathrm{m}$.
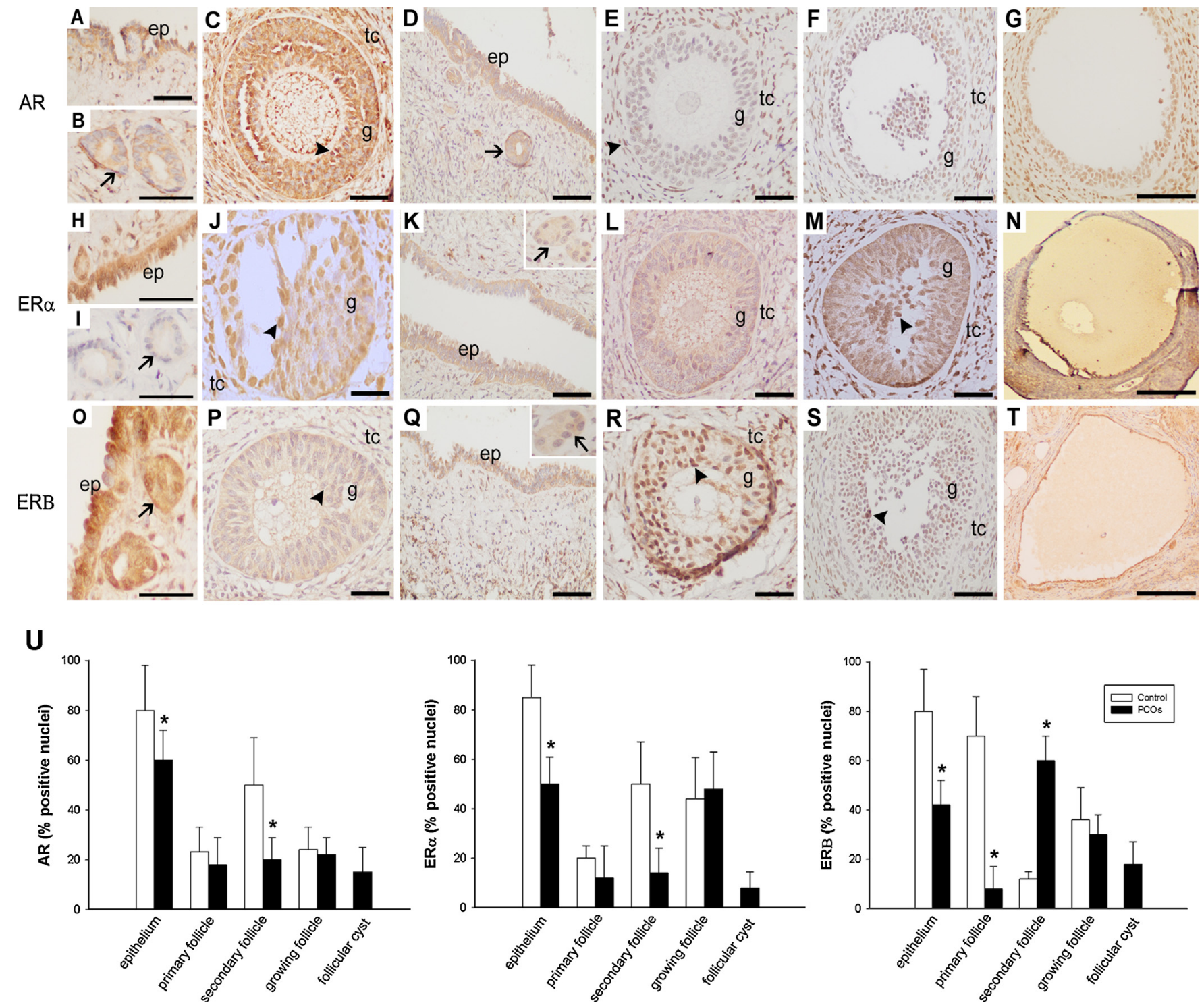

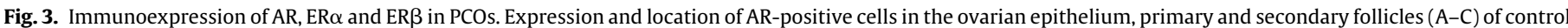

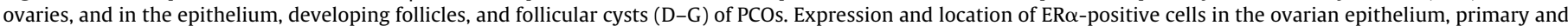

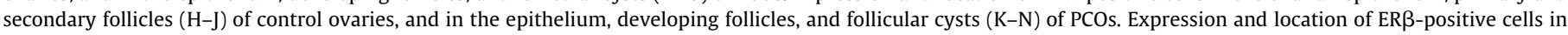

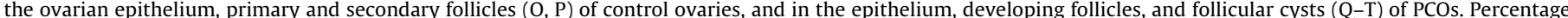

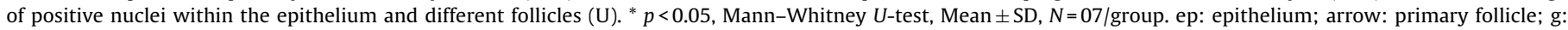
granulosa cells; tc: theca cells; arrowhead: positive immunostaining. Bar $=20 \mu \mathrm{m}$; For cysts, $\operatorname{Bar}=50 \mu \mathrm{m}$. 
Table 2

Immunolocalization and intensity of sex steroid receptors (AR, ER $\alpha$, and ER $\beta$ ) in the control and PCOs animals ( $n=07 /$ group).

\begin{tabular}{|c|c|c|c|c|c|c|}
\hline \multirow[t]{2}{*}{ Location } & \multicolumn{2}{|l|}{ AR } & \multicolumn{2}{|l|}{$\mathrm{ER} \alpha$} & \multicolumn{2}{|l|}{$\mathrm{ER} \beta$} \\
\hline & Control & PCOs & Control & PCOs & Control & PCOs \\
\hline Epithelium & ++ & + & ++ & + & ++ & + \\
\hline Primary follicles & + & + & + & + & ++ & + \\
\hline $\begin{array}{l}\text { Secondary follicles } \\
\text { (g) }\end{array}$ & ++ & + & ++ & + & + & +++ \\
\hline (tc) & ++ & ++ & ++ & + & - & + \\
\hline $\begin{array}{l}\text { Growing follicles } \\
\text { (g) }\end{array}$ & + & + & ++ & ++ & ++ & ++ \\
\hline$(\mathrm{tc})$ & + & + & ++ & ++ & - & - \\
\hline Follicular cysts & ++ & & + & & ++ & \\
\hline
\end{tabular}

Reactions were as strong $(+++)$, moderate $(++)$, weak $(+)$, and absent $(-)$. g: granulosa cells; tc: theca cells.

epithelium and secondary follicles, a moderate immunoexpression to AR was found in theca cells of the secondary follicles and in follicular cysts (Table 2, Fig. 3C, E, G, and U). ER $\alpha$-positive cells were lower in the epithelium and secondary follicles, whereas granulosa and theca cells of the growing follicles showed a moderate reaction to ER $\alpha$ (Table 2, Fig. 3H-M, and U). Only a few ER $\alpha$-positive cells showing low intensity were found in the cysts (Table 2, Fig. $3 \mathrm{~N}$ ). While ER $\beta$ levels were reduced in the epithelium and primary follicles, a strong upregulation of ER $\beta$ was observed in the granulosa cells of secondary follicles, whereas growing follicles and cysts presented a moderate immunoexpression (Table 2, Fig. $3 \mathrm{O}-\mathrm{U}$ ).

\subsection{Pro-apoptotic and anti-apoptotic molecules in different} follicles of PCOs

Apoptotic and anti-apoptotic proteins were evaluated in developing follicles and in follicular cysts. In PCOs, BAX was upregulated in the ovarian epithelium, primary follicles, and in the wall of follicular cysts (Table 3, Fig. 4A1-A7). On the other hand, active caspase-3 was significantly downregulated in the ovarian epithelium and primary follicles compared to control ovaries. While growing follicles had a strong immunoexpression of active caspase- 3 mainly in the granulosa cells, no positive immunoreaction was found in the follicular cysts (Table 3, Fig. 4B1-B7). Anti-apoptotic Bcl-2 and survivin levels were increased in the ovarian epithelium and primary follicles compared to control ovaries. Only survivin was upregulated in secondary and growing follicles with an intense immunoreaction in granulosa and theca cells. In growing follicles and follicular cysts, Bcl-2 had a moderate and diffuse immunoreaction in the cytoplasm of these cells, whereas survivin was overexpressed in the wall of follicular cysts (Table 3, Fig. 4C1-D7 and E). Negative immunohistochemical controls without primary antibodies were used and showed no positive reaction.

\section{Discussion}

Ovarian cysts are fluid-filled structures of different sizes inside the ovary (Johnston et al., 2001). Our data demonstrated that multiple cysts were often present in both ovaries, and the number of cysts varied from 4 to 24, considering their different sizes. Most cysts were 2-9 $\mathrm{mm}$ in size (average size of $2.8-7.2 \mathrm{~mm}$ in diameter). Due to these ovarian follicular cysts, the bitches had showed high serum E2 levels in accordance to the literature regarding PCOs-related hyperestrogenism (Johnston et al., 2001; Knauf et al., 2014), which further resulted in prolonged estrus. Physiological estrus cycle in bitches is around 2-4 weeks (Feldman and Nelson, 2004a) followed by metaestrus and anestrus, and prolonged estrus is defined as persisting for longer than 28 days (Feldman and Nelson, 2004b).

To better understand the role of inhibin B on these PCOs, fluorescence assays were conducted to verify their localization in different follicle sizes. Unexpectedly, an intense immunolabeling was observed in primary and $2-5 \mathrm{~mm}$ follicles as compared to a weak reaction in growing and $6-9 \mathrm{~mm}$ follicles. There seems to be a consensus that inhibin B, produced by the granulosa cells of normal and PCOs follicles, acts in an endocrine manner to suppress FSH, and locally stimulates follicle development (Welt et al., 2002). Although some studies have correlated PCOs with elevation in inhibin levels, there are many inconsistent results found in humans and animals regarding the activity of inhibin (Welt et al., 2002; Tsigkou et al., 2008). In our study, we believe that the follicle development may be triggered by another mechanism(s) independent of inhibin B.

The ovarian surface epithelium (OSE) showed hyperplasia with no cellular or nuclear atypias. High E2 levels and expression of their receptors ER $\alpha$ and ER $\beta$ were strongly related to hypertrophy and hyperplasia in mouse ovaries (Gulliver and Hurst, 2012). Because the canine PCOs were accompanied by increased E2 levels and epithelial expression of their receptors, hyperplasia but not hypertrophy may be one of the cellular responses to this E2-ER signaling.

Despite their clinical significance, few reports have focused on the relationship between PCOs and expression of sex steroid receptors and apoptotic proteins. We have reported a differential expression of AR, ER $\alpha$ and $\beta$, and apoptotic molecules (BAX, caspase-3, Bcl-2 and survivin) in specific follicle subtypes of canine PCOs. Here, our results supported an increased AR levels in the theca cells of secondary follicles and in the cysts wall. The excessive androgen levels in ovary can inhibit follicle development and, in turn, makes it difficult to form a dominant follicle. Conversely, high E2 levels secreted by early follicles affect the hypothalamus and pituitary in a positive feedback for LH secretion (Yu et al.,

Table 3

Immunolocalization and intensity of apoptosis-related proteins (BAX, Active caspase-3, Bcl-2 and Survivin) in the control and PCOs animals ( $n=07 /$ group).

\begin{tabular}{|c|c|c|c|c|c|c|c|c|}
\hline \multirow[t]{2}{*}{ Location } & \multicolumn{2}{|l|}{ BAX } & \multicolumn{2}{|c|}{ Active Caspase-3 } & \multicolumn{2}{|l|}{$\mathrm{Bcl}-2$} & \multicolumn{2}{|l|}{ Survivin } \\
\hline & Control & PCOs & Control & PCOs & Control & PCOs & Control & PCOs \\
\hline Epithelium & + & ++ & +++ & + & ++ & +++ & + & +++ \\
\hline Primary follicles & + & ++ & +++ & + & ++ & +++ & + & +++ \\
\hline $\begin{array}{l}\text { Secondary follicles } \\
\text { (g) }\end{array}$ & + & + & ++ & + & - & + & + & +++ \\
\hline (tc) & ++ & + & + & + & + & + & + & +++ \\
\hline $\begin{array}{l}\text { Growing follicles } \\
\text { (g) }\end{array}$ & + & + & + & +++ & + & ++ & + & +++ \\
\hline (tc) & + & + & + & + & + & ++ & + & +++ \\
\hline Follicular cysts & & +++ & & - & & ++ & & +++ \\
\hline
\end{tabular}

Reactions were as strong (+++), moderate (++), weak (+), and absent (-). g: granulosa cells; tc: theca cells. 

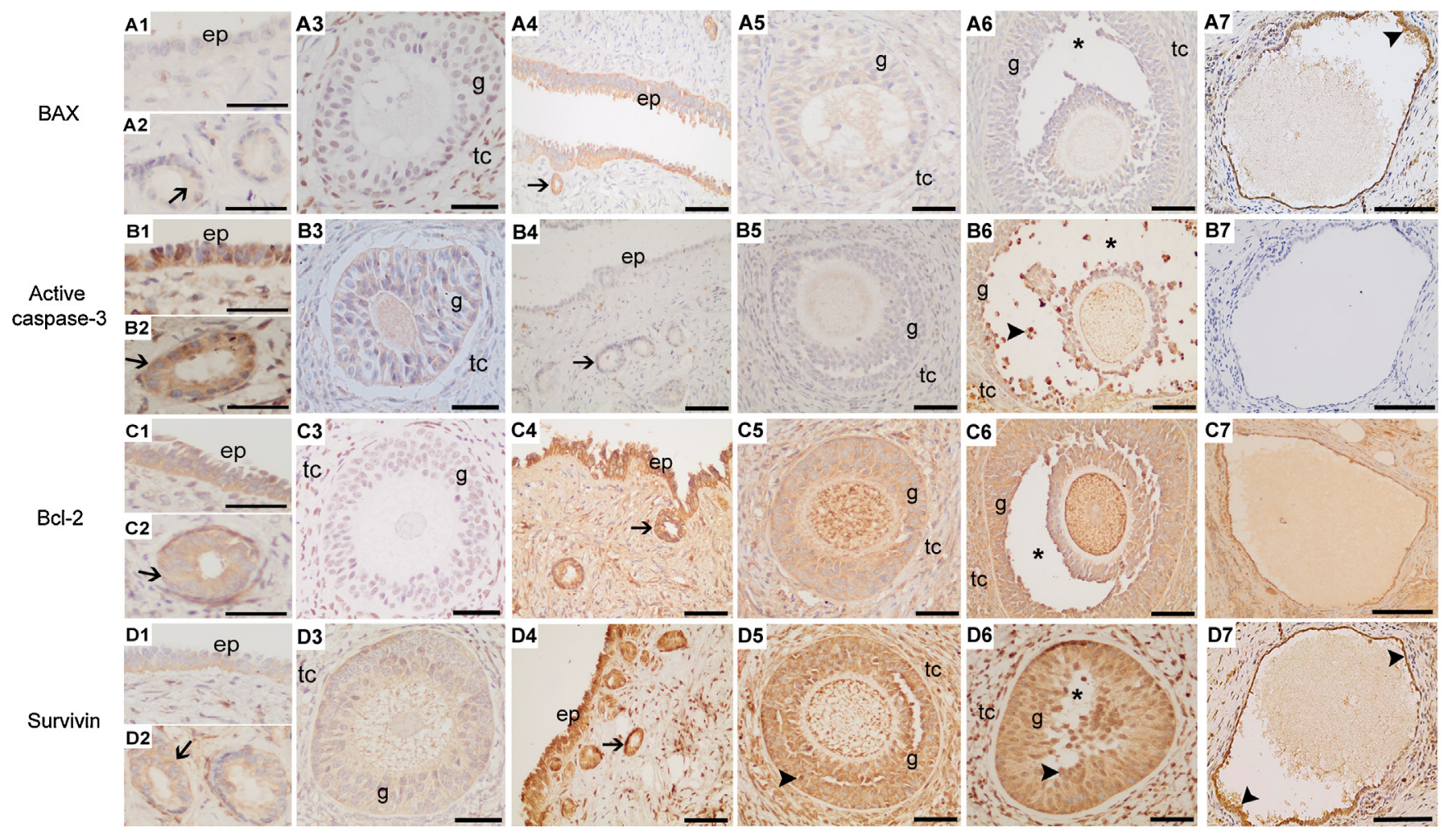

Active

caspase-3
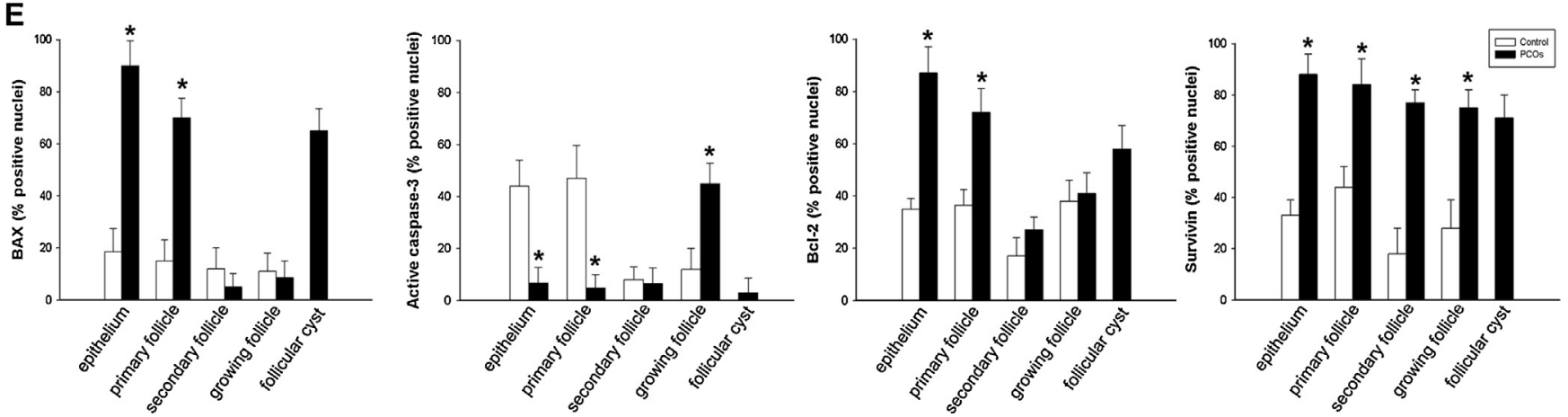

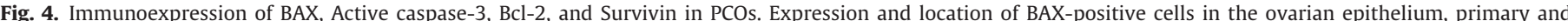

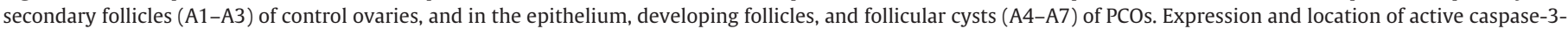

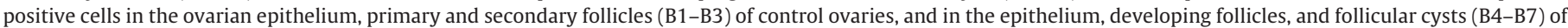

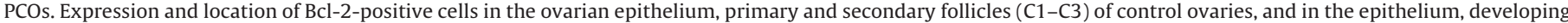

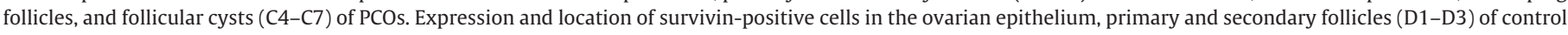

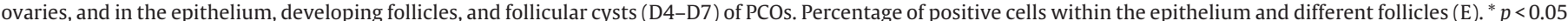

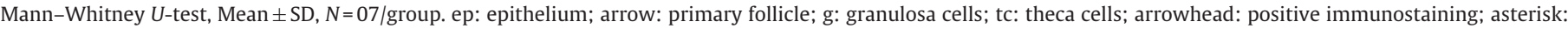
follicular antrum. Bar $=20 \mu \mathrm{m}$; For cysts, $\mathrm{Bar}=50 \mu \mathrm{m}$.

2014). The increase in AR expression may probably be due to an indirect effect of LH on theca cells of these follicles; however, the limited expression of AR in other follicles may be reducing the activity of androgens or even its synthesis. Both ER $\alpha$ and ER $\beta$ exert essential regulatory mechanisms in orchestrating folliculogenesis, luteogenesis, and ovulation process (Chuffa et al., 2011, 2013a,b). As previously confirmed, the expression of ER $\beta$ is higher than ER $\alpha$ in different follicles of women with PCOs (Artimani et al., 2015). In this regard, we found high levels of ER $\beta$ in the granulosa cells of secondary follicles, but a moderate reaction in growing follicles and cysts. This allow us to consider that ER $\beta$ is highly expressed during early follicle development and downregulated toward the cystic formation. Otherwise, ER $\alpha$ expression seems to be unaltered among the follicles. The role of ER $\alpha$ in PCOs is not well elucidated and requires new approaches involving proper and specific functions. Notably, this is the first study to characterize these components in PCOs through an immunohistochemical assay.

There is a variety of experimental models for studying PCOs. The administration of estradiol valerate as well as dihydrotestosterone and letrozole can mimic the syndrome as a result of metabolic and physiological disturbances and a sudden appearance of PCOs (Mahajan, 1988; Rezvanfar et al., 2014; Nikolić et al., 2015). Recently, Lombardi et al. (2014) proposed a model of PCOs submitting rats to constant lighting at $400 \mathrm{~lx}$ for a period of 60 consecutive days. They observed persistent estrus, absence of corpora lutea and several ovarian cysts due to a fail in the preovulatory LH surge. Similar to our results, Lombardi et al. (2014) reported higher levels of cleaved caspase-3 in granulosa cells and lower levels in the theca cells of follicles, suggesting stromal accumulation of interstitial cells derived from theca cells that broken off during its intense proliferation activity. This event may contribute to the 
maintenance of a static state, leading to the persistence of large cysts surrounded by considerable amount of interstitial cells and adapted to a microenvironment highly dependent on hormonal levels. Interestingly, dogs with PCOs presented high levels of E2 and $\mathrm{T}$ as shown in other animal models and humans. Furthermore, despite the developing follicles appeared to be continuously expressing hormone receptors in PCOs, the lower levels of these receptors in the cysts wall suggest the imbalance in hormonereceptor responsiveness; however, the critical period and the key elements for a complete understanding of how a cyst develops in a dog remain unclear. Although it is widely accepted that disorders of the hypothalamic-pituitary-ovary axis represent an important factor for cystic formation, delay of follicle regression after ovulation failure may be considered an alternative cause of cysts (Salvetti et al., 2009). Considering the hormonal-receptor interplay associated to the apoptotic and anti-apoptotic signals, we believed that the combination of these conditions are responsible for cyst formation and maintenance.

The granulosa cells are lost in the late stage of cystic follicle (Isobe and Yoshimura, 2007). Because there was a negative correlation between anti-apoptotic proteins and caspase- 3 in granulosa cells of the dog cysts, probably these cells are trying to escape from cell death in an early stage. We have showed that BAX expression had a high intensity in follicular cysts while Bcl-2 and survivin were increased in different follicular stages. Interestingly, Bas et al. (2011) demonstrated by immunohistochemistry that the expression of $\mathrm{Bcl}-2$ and BAX are mainly localized in granulosa cells of antral follicles. Also, they proposed that BAX expression was increased in these follicles of PCOs. It is important to consider that a balance between pro- and anti-apoptotic components exists, and an overexpression of pro-apoptotic molecules (e.g. BAX) may lead the cells to apoptosis. Our results demonstrated that Bcl2 immunostaining was weak in secondary follicles and increased toward follicle cysts. To evaluate the effective role of $\mathrm{Bcl}-2$ in cyst formation, it would be essential to investigate the complete development stage of the follicles and in which stage transition the cells overexpress Bcl-2. Notably, high Bcl-2 levels and low active caspase- 3 in the follicular cysts probably ensure that granulosa cells do not activate apoptotic signaling (Isobe and Yoshimura, 2007), which implies in maintenance of the cysts. According to Isobe and Yoshimura (2007), this low frequency in the cysts is different from atretic follicles, in which a high rate of apoptotic cells in the granulosa and thecal layers are observed. Due to this low apoptotic frequency and weak proliferative activity, the cystic follicle grows slowly without degeneration, while maintain a static condition for long-term persistence. Besides high Bcl-2 levels, survivin also showed a marked activity in granulosa and theca cells of secondary follicles and in follicular cysts. This anti-apoptotic signaling can make the cysts able to evade apoptosis. In cultured granulosa cells from growing follicle, the survivin expression was elevated specifically during the G2/M phase of cell cycle together with a severe inhibition of caspase- 3 activity, acting as a bifunctional protein (Johnson et al., 2002). Indeed, to conclude on the role of survivin in suppressing caspase-3 activity in follicular cysts, inhibition and activation assays are required for granulosa and theca cells.

In summary, no correlation between inhibin B and follicle development was evidenced regarding the follicle sizes of adult dogs with PCOs. Otherwise, sex steroid receptors and apoptosis-related proteins were differentially regulated in the follicles. AR, ER $\alpha$, and ER $\beta$ showed to be continuously expressed in developmental follicles, but only a moderate reaction to AR and ER $\beta$ was found in the follicular cysts. Anti-apoptotic proteins were upregulated in early and late follicular development, and active caspase- 3 was downregulated in primary and secondary follicles and follicular cysts, ensuring the long-term permanency of the ovarian cysts in dogs.
Further studies are needed to better explain the mechanism(s) related to apoptotic signaling pathway in follicular cysts.

\section{Disclosure statement}

The authors have nothing to disclose.

\section{Funding}

Grant sponsors: CAPES and FAPESP.

\section{Author contributions}

LGAC, AFML: collected and analyzed the data, drafted the manuscript, and conceived the main idea of the study. They also participated in the acquisition of data and in the design and intellectual conception of the study. Authors performed the statistical analysis and approved the final version of the manuscript.

\section{Acknowledgments}

We are grateful to Mr Gelson Rodriguez from Department of Anatomy, IBB/UNESP, Botucatu-SP, for excellent technical support.

\section{References}

Artimani, T., Saidijam, M., Aflatoonian, R., Amiri, L., Ashrafi, M., Shabab, N. Mohammadpour, N., Mehdizadeh, M., 2015. Estrogen and progesterone receptor subtype expression in granulosa cells from women with polycystic ovary syndrome. Gynecol. Endocrinol. 21, 1-5.

Bas, D., Abramovich, D., Hernandez, F., Tesone, M., 2011. Altered expression of $\mathrm{Bcl}-2$ and Bax in follicles within dehydroepiandrosterone-induced polycystic ovaries in rats. Cell Biol. Int. 35, 423-429.

Bogovich, K., 2007. Obligatory roles for follicle-stimulating hormone (FSH) estradiol and androgens in the induction of small polyfollicular ovarian cysts in hypophysectomized immature rats. Endocrine 31, 179-192.

Chuffa, L.G., Fioruci-Fontanelli, B.A., Mendes, L.O., Fávaro, W.J., Pinheiro, P.F. Martinez, M., Martinez, F.E., 2013a. Characterization of chemically induced ovarian carcinomas in an ethanol-preferring rat model: influence of long-term melatonin treatment. PLoS ONE 8, e81676.

Chuffa, L.G., Padovani, C.R., Martinez, F.E., 2009. Ovarian structure and hormonal status of the UChA and UChB adult rats in response to ethanol. Maturitas 62, 21-29.

Chuffa, L.G., Seiva, F.R., Fávaro, W.J., Amorim, J.P., Teixeira, G.R., Mendes, L.O., Fioruci-Fontanelli, B.A., Pinheiro, P.F., Martinez, M., Martinez, F.E., 2013b. Melatonin and ethanol intake exert opposite effects on circulating estradiol and progesterone and differentially regulate sex steroid receptors in the ovaries, oviducts, and uteri of adult rats. Reprod. Toxicol. 39, 40-49.

Chuffa, L.G., Seiva, F.R., Fávaro, W.J., Teixeira, G.R., Amorim, J.P., Mendes, L.O., Fioruci, B.A., Pinheiro, P.F., Fernandes, A.A., Franci, J.A., Delella, F.K., Martinez, M., Martinez, F.E., 2011. Melatonin reduces LH, 17 beta-estradiol and induces differential regulation of sex steroid receptors in reproductive tissues during rat ovulation. Reprod. Biol. Endocrinol. 9, 108.

Feldman, E.C., Nelson, R.W., 2004a. Ovarian cycle and vaginal cytology. In: Feldman, E.C., Nelson, R.W. (Eds.), Canine and Feline Endocrinology and Reproduction. Saunders, St. Louis, MO, pp. 752-774.

Feldman, E.C., Nelson, R.W., 2004b. Infertility, associated breeding disorders, and disorders of sexual development. In: Feldman, E.C., Nelson, R.W. (Eds.), Canine and Feline Endocrinology and Reproduction. Saunders, St. Louis, MO, pp. $868-900$

Gulliver, L.S.M., Hurst, P.R., 2012. Repeat estradiol exposure differentially regulates protein expression patterns for estrogen receptor and E-cadherin in older mouse ovarian surface epithelium: implications for replacement and adjuvant hormone therapies? Steroids 77, 674-685.

Isobe, N., Yoshimura, Y., 2007. Deficient proliferation and apoptosis in the granulosa and theca interna cells of the bovine cystic follicle. J. Reprod. Dev. 53 , 1119-1124.

Jiang, Z.Z., Hu, M.W., Wang, Z.B., Huang, L., Lin, F., Qi, S.T., Ouyang, Y.C., Fan, H.Y. Schatten, H., Mak, T.W., Sun, Q.Y., 2014. Survivin is essential for fertile egg production and female fertility in mice. Cell Death Dis. 27, e1154.

Johnson, A.L., Langer, J.S., Bridgham, J.T., 2002. Survivin as a cell cycle-related and antiapoptotic protein in granulosa cells. Endocrinology 143, 3405-3413.

Johnston, S.D., Kustritz, M.V.R., Olson, P.N.S., 2001. Canine and Feline Theriogenology. Saunders, Philadelphia, pp. p.195.

Kirchhoff, C., 2002. The dog as a model to study human epididymal function at a molecular level. Mol. Hum. Reprod. 8, 695-701.

Knauf, Y., Bostedt, H., Failing, K., Knauf, S., Wehrend, A., 2014. Gross pathology and endocrinology of ovarian cysts in bitches. Reprod. Domest. Anim. 49, 463-468. 
Lombardi, L.A., Simões, R.S., Maganhin, C.C., Baracat, M.C., Silva-Sasso, G.R., Florencio-Silva, R., Soares Jr., J.M., Baracat, E.C., 2014. Immunohistochemical evaluation of proliferation, apoptosis and steroidogenic enzymes in the ovary of rats with polycystic ovary. Rev. Assoc. Med. Bras. 60, 349-356.

Lombardi, L.A., Simões, R.S., Maganhin, C.C., da Silva, C.F., Maciel, G.A., Baracat, E.C., Soares Jr., J.M., 2012. Morphology of the interstitial cells of rat polycystic ovaries: an experimental study. Rev. Bras. Ginecol. Obstet. 34, 323-328.

Magoffin, D.A., Jakimiuk, A., 1998. Inhibin A, inhibin B and activin A concentrations in follicular fluid from women with polycystic ovary syndrome. Hum. Reprod. $13,2693-2698$

Mahajan, D.K., 1988. Polycystic ovarian disease: animal models. Endocrinol. Metab. Clin. N. Am. 17, 705-732

Nikolić, M., Macut, D., Djordjevic, A., Veličković, N., Nestorović, N., Bursać, B., Antić I.B., Macut, J.B., Matić, G., Vojnović Milutinović, D., 2015. Possible involvement of glucocorticoids in $5 \alpha$-dihydrotestosterone-induced PCOS-like metabolic disturbances in the rat visceral adipose tissue. Mol. Cell Endocrinol. 399, 22-31.

Palioura, E., Diamanti-Kandarakis, E., 2013. Industrial endocrine disruptors and polycystic ovary syndrome. J. Endocrinol. Invest. 36, 1105-1111.

Rezvanfar, M.A., Shojaei Saadi, H.A., Gooshe, M., Abdolghaffari, A.H., Baeeri, M. Abdollahi, M., 2014. Ovarian aging-like phenotype in the hyperandrogenism-induced murine model of polycystic ovary. Oxid. Med. Cell. Longev. 2014, e948951.

Salvetti, N.R., Panzani, C.G., Gimeno, E.J., Neme, L.G., Alfaro, N.S., Ortega, H.H., 2009. An imbalance between apoptosis and proliferation contributes to follicular persistence in polycystic ovaries in rats. Reprod. Biol. Endocrinol. 7, 68.
Singhasena, W., Pantasri, T., Piromlertamorn, W., Samchimchom, S., Vutyavanich, T., 2014. Follicle-stimulating hormone receptor gene polymorphism in chronic anovulatory women, with or without polycystic ovary syndrome: a cross-sectional study. Reprod. Biol. Endocrinol. 12, 86.

Tilly, J.L., 1996. Apoptosis and ovarian function. Rev. Reprod. 1, 162-172.

Tsigkou, A., Luisi, S., De Leo, V., Patton, L., Gambineri, A., Reis, F.M., Pasquali, R., Petraglia, F., 2008. High serum concentration of total inhibin in polycystic ovary syndrome. Fertil. Steril. 90, 1859-1863.

Welt, C.K., Taylor, A.E., Martin, K.A., Hall, J.E., 2002. Serum inhibin B in polycystic ovary syndrome: regulation by insulin and luteinizing hormone. J. Clin. Endocrinol. Metab. 87, 5559-5556.

Wu, X.Q., Xu, S.M., Liu, J.F., Bi, X.Y., Wu, Y.X., Liu, J., 2014. Association between FSHR polymorphisms and polycystic ovary syndrome among Chinese women in north China. J. Assist. Reprod. Genet. 31, 371-377.

Xita, N., Georgiou, I., Tsatsoulis, A., 2002. The genetic basis of polycystic ovary syndrome. Eur. J. Endocrinol. 147, 717-725.

Xita, N., Tsatsoulis, A., 2006. Review: fetal programming of polycystic ovary syndrome by androgen excess: evidence from experimental, clinical, and genetic association studies. J. Clin. Endocrinol. Metab. 91, 1660-1666.

Yu, J., Zhai, D., Hao, L., Zhang, D., Bai, L., Cai, Z., Yu, C., 2014. Cryptotanshinone reverses reproductive and metabolic disturbances in PCOS model rats via regulating the expression of CYP17 and AR. Evid. Based Complement Alternat. Med. 2014, 670743. 